\title{
Cognitive Behaviour Assessment in Chronic Non Specific Low Back Pain: A Narrative Review
}

\author{
Seema Saini ${ }^{1,2^{*}}$, Paresh Golwala, M.S. ${ }^{3}$, Lata Parmar, PhD ${ }^{4}$, Devashish Tiwari, PhD ${ }^{5}$, and Tushar J \\ Palekar, PhD ${ }^{6}$
}

${ }^{1}$ PhD Scholar, Sumandeep Vidyapeeth, Vadodara, India

${ }^{2}$ Professor, Dr. D. Y. Patil College of Physiotherapy, Dr. D. Y. Patil Vidyapeeth, Pune, India

${ }^{3}$ Dean, Smt. B.K.Shah Medical Institute \& Research Centre, Sumandeep Vidyapeeth, Vadodara, India

${ }^{4}$ Professor \& Principal, College of Physiotherapy, Sumandeep Vidyapeeth, Vadodara, India

${ }^{5}$ Assistant Professor, Simmons University, Boston, Massachusetts, United States

${ }^{6}$ Professor \& Principal, Dr. D. Y. Patil College of Physiotherapy, Dr. D.Y.Patil Vidyapeeth, Pune, India

*Corresponding author: Seema Saini, Professor, Dr. D. Y. Patil College of Physiotherapy, Dr. D. Y. Patil Vidyapeeth, Pune, India, Tel: +918087564345

\begin{abstract}
Background: Literature showed that patients with Chronic Low Back Pain (CLBP) have slowed speeds of information processing and working memory. Methods for assessment of cognition behaviour are decisive for the implementation Of Cognitive behavioural therapies. There remains a large component of the adherence process not assessed, while treating non specific chronic Low back Pain, and the known role for treatment appraisals and beliefs necessitating the pursuit of improved assessment methods. The purpose of this review is to analyze the content and psychometric properties of the available literature in regard to various Cognitive behaviour assessment tools available for patients with CLBP.

Objective: To undertake a narrative review of Cognitive Behaviour Assessment for the consideration of their role in emotional disorders, and the question of the accessibility of cognitive information when treating chronic conditions like Low Back Pain.

Methods: Keyword searches of Medline, CINAHL, ISI, and IBSS databases. Manual searches of other relevant journals and reference lists of primary articles.

Results: Seven articles were included out of 13 articles. A total of 1261 participants with chronic low back pain took part in the studies. The relation between pain area and other psychological factors such as anxiety, kinesiophobia, catastrophizing, memory disturbances and concentration difficulties were reported.
\end{abstract}

Conclusion: The findings suggest that only depression might have a weak relation with the pain area. A definitive answer on the relation of psychological factors and pain area is not available. Future studies that investigate sensory, psychological, emotional, cognitive and behavioural aspects, and also more accurate methods of cognition assessment, are needed.

\section{Keywords}

Cognitive behavior assessment, Chronic pain, Low back pain

\section{Background}

Chronic pain (pain persisting for $\geq 3$ months) has been reported to have a negative impact on cognition, including working memory, long-term memory and recognition, attention, executive functions and decision making [1].

Studies have suggested that an increasingly negative orientation towards pain and fear of movement, or reinjury, are highly important in the etiology of chronic low back pain (CLBP) [2]. Therefore it has been suggested CLBP has significant association with psychological factors along with contributing mechanical factors [3]. Cognitive Behavioural Therapy (CBT) can help to manage the problems by changing the way patients would

Citation: Saini S, Golwala P, Parmar L, Tiwari D, Palekar TJ (2020) Cognitive Behaviour Assessment in Chronic Non Specific Low Back Pain: A Narrative Review. Int J Cogn Behav 3:009. doi.org/10.23937/26903172/1710009

Accepted: October 13, 2020: Published: October 15, 2020

Copyright: (C) 2020 Saini S, et al. This is an open-access article distributed under the terms of the Creative Commons Attribution License, which permits unrestricted use, distribution, and reproduction in any medium, provided the original author and source are credited. 
think and behave. The assessment of cognitive behaviour is the foundation of CBT as it involves a range of concepts, theories, models and styles of working, rather than a single school of thought. One of the important challenges to be met within current CBT approaches to chronic pain is the challenge of assessment processes. Research has primarily been focused on the effectiveness of CBT and limited research is available on the valid assessment methods to identify the factors that will change the thoughts and behaviour of patients with CLBP [3-7].

Pain and cognition are inherently linked. Under normal circumstances, acute pain acts as a warning signal and protective mechanism to prevent harmful tissue damage [4]. Therefore, it is associated with memory retrieval relating to previous painful experiences as well as adaptive learning and active decision-making, collectively termed the cognitive-evaluative dimension of pain [4]. It is hypothesized that neural substrates involved in cognition and pain processing are linked, and that the two systems modulate one another reciprocally [5]. An increase in pain would lead to impaired cognitive function, and an increasing non pain-related cognitive load could reduce perceived pain [6].

The assessment of cognition is an integral component of CBT. Numerous domains are evaluated by cognitive assessments including memory, concentration, processing speed, language, and reasoning capabilities. There are several cognitive tests that involve answering a series of questions and/or performing simple cognitive tasks. These tests are instrumental in measuring mental functions, such as memory, language, and the ability to recognize objects.

A better understanding of the interaction between pain and cognition is necessary to achieve therapeutic goals. However, limited cognitive assessment tools are available to evaluate effectiveness of CBT [8].

Different models including Psychological Flexibility Model and Fear-Avoidance Model (FAM) have been reported to assess cognition. Psychological flexibility is founded on the six core Acceptance and Commitment Therapy (ACT) processes: Diffusion, acceptance, present moment, self-as-a-content, values, and committed action. However, its effectiveness on the pain component is still questionable. The FAM describes how individuals develop chronic, musculoskeletal pain as a result of avoidant behaviour based on fear. There is clear evidence that fear-avoidance is closely related to increased pain, physical disability, and long-term sick leave in patients living with chronic pain [9]. However, there is still considerable debate among researchers about the FAM, given its applicability in CLBP [10].

While it is argued that FAM may be too simplistic for every situation involving fear, discomfort, and chronic pain [11]. It is generally acknowledged across the heal- thcare community as a means to diagnosing and understanding how humans positively and negatively react to fear [12]. Hence, there is a need to determine if these measures can be used as a valid assessment tool for cognitive behaviour in CLBP patients? [13-16].

Indeed, though it may be only one of the problems faced by cognitive-behaviour therapists, since limited research is available on the assessment tools for the cognition in $\mathrm{CBT}$, there is a need to examine the existing outcome measures. The aim of this study is to provide a narrative review of research conducted on assessment tools available for identifying cognition in patients with CLBP that may help us to implement the CBT with the better outcome.

\section{Methods}

This narrative review is based on the literature that came to our attention on or before September, 2019. Studies included in the review were identified by keyword searches of Medline, Pubmed, CINAHL, ISI, and IBSS databases. Keywords searched included cognitive behaviour assessment, chronic pain, chronic low back pain, cognitive behaviour therapy.

\section{Eligibility criteria}

Studies were included in this review if they met following criteria: 1) The study was done on adults and older adults; 2) Included patients diagnosed with a chronic Low Back pain; 3) Presented the association between pain area and psychological or behavioural measurements and; 4) Full text articles of original research published in English had to be available. The studies were excluded if they did not meet the above criteria. (Table 1 and Figure 1) [12-14,17-20].

\section{Results}

Out of seven articles included ( $\mathrm{N}=1261$ participants) 2 articles used 20 items Center for Epidemiological Studies Depression Scale (CES-D) scale for measuring depression in CLBP. Depression has a strong influence on pain intensity and degree of disability in CLBP patients. To reduce the pain and disability associated with CLBP, screening and early management of depression are essential. CES-D found to have adequate reliability and validity [17].

Spindler M, et al., used the Allgemeine Depressionsskala (ADS-K) which is the short form of the German version of the Center for Epidemiological Studies Depression Scale (CES-D). The questionnaire consists of 15 items assessing depressive symptoms in chronic pain patients. The internal consistency is 0.89 , the test having reliability of 0.81 [13].

One study evaluated the relationship between change in pain cognitions measured by the Survey of Pain Attitudes (SOPA) and the pain catastrophizing scale (PCS) and change in physical performance, measured by 


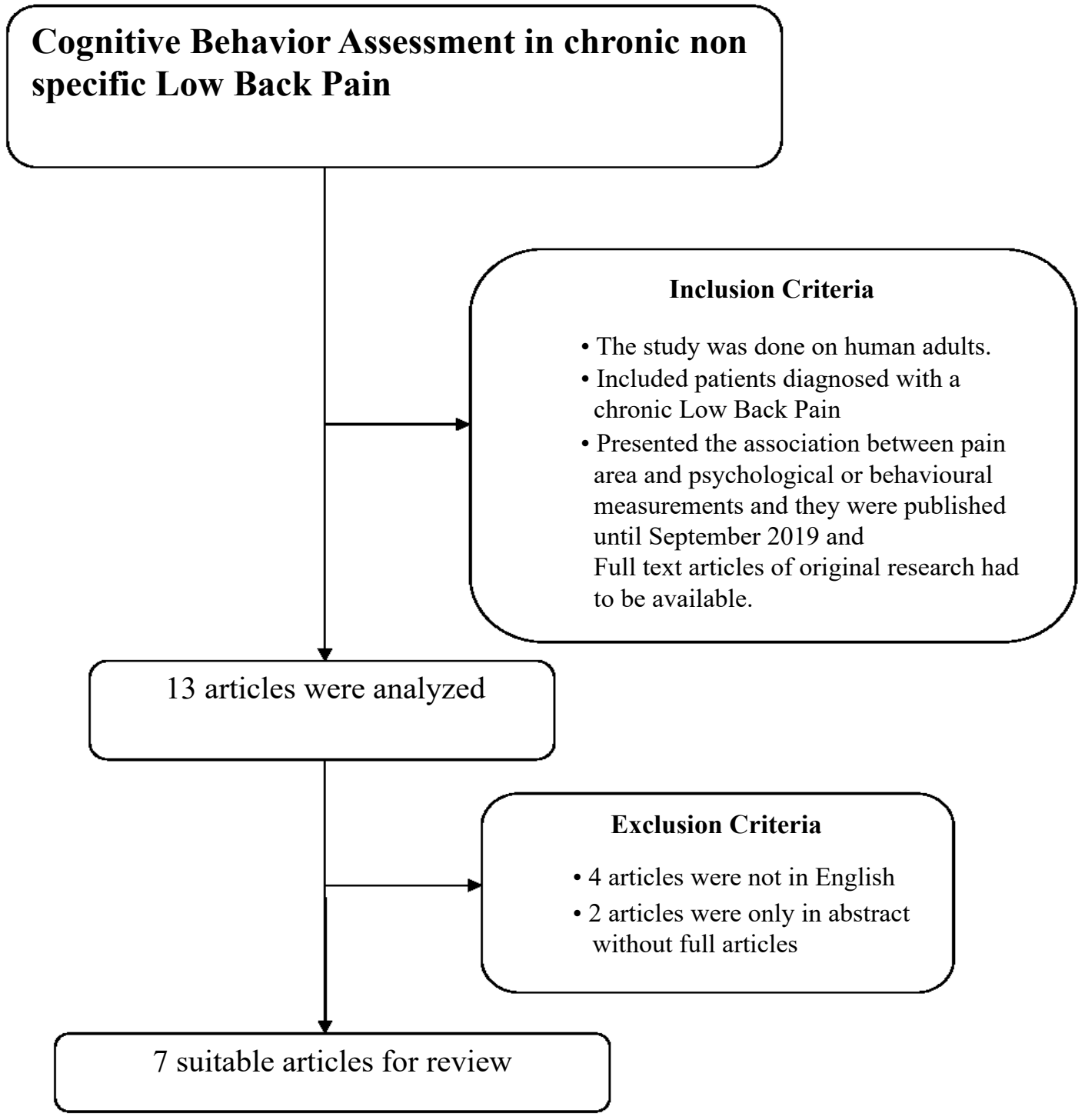

Figure 1: Search and selection process applied in this review.

Table 1: Characteristics of included articles.

\begin{tabular}{|c|c|c|c|c|}
\hline Author \& Date & Outcome Measures & Sample & Conclusion & Psychometric Properties \\
\hline $\begin{array}{l}\text { Moseley GL, } 2004 \\
\text { [12] }\end{array}$ & $\begin{array}{l}\text { The brief survey of } \\
\text { pain attitudes (SOPA) } \\
\text { The pain } \\
\text { catastrophising scale } \\
\text { (PCS) }\end{array}$ & $\begin{array}{l}N=121 \text { CLBP } \\
\text { Age: } 36-68\end{array}$ & $\begin{array}{l}\text { Change in pain cognitions } \\
\text { is associated with change in } \\
\text { physical performance, even } \\
\text { when there is no opportunity } \\
\text { to be physically active. } \\
\text { Unhelpful pain cognitions } \\
\text { should be considered } \\
\text { when interpreting physical } \\
\text { assessments. }\end{array}$ & $\begin{array}{l}\text { SOPA -Brief: Four domains } \\
\text { had good Cronbach's alpha } \\
\text { values }(0.74-0.85) \text { and three } \\
\text { had moderate }(0.58-0.65) \\
\text { PCS: Cronbach's } \alpha=0.92(95 \% \\
\mathrm{Cl}=0.91-0.93) \\
\text { For total scale: Test-retest } \\
\text { reliability = Spearman } \rho=0.88, \\
95 \% \mathrm{Cl}=0.83-0.93) \text { Data was } \\
\text { not reported for the subscales. }\end{array}$ \\
\hline $\begin{array}{l}\text { Paul Karoly, et al. } \\
2008 \text { [17] }\end{array}$ & $\begin{array}{l}\text { 4-item Self-Efficacy } \\
\text { scale of Goal } \\
\text { Systems Assessment } \\
\text { Battery (GSAB ) } \\
\text { Center for } \\
\text { Epidemiological } \\
\text { Studies Depression } \\
\text { Scale(CES-D) }\end{array}$ & $\begin{array}{l}n=100 \text { CLBP } \\
\text { Age: } 30-65\end{array}$ & $\begin{array}{l}\text { Clinical pain specialists should } \\
\text { treat pain-induced fear as a } \\
\text { means of forestalling disability } \\
\text { and depression, and that they } \\
\text { should also seek to modify } \\
\text { how CLBP patients think } \\
\text { about and organize their life } \\
\text { goals }\end{array}$ & $\begin{array}{l}\text { GSAB: Cronbach's } \alpha=0.86 \text {. } \\
\text { CES -D: Internal consistency } \\
\text { reliability as estimated by } \\
\text { coefficient a was } 0.86 \text {. Retest } \\
\text { reliability of } 0.67\end{array}$ \\
\hline
\end{tabular}




\begin{tabular}{|c|c|c|c|c|}
\hline $\begin{array}{l}\text { Nadar MS, et al. } \\
2016 \text { [18] }\end{array}$ & $\begin{array}{l}\text { Visual analogue scale } \\
\text { (VAS) } \\
\text { Contextual Memory } \\
\text { Test(CMT) Short-term } \\
\text { memory and long } \\
\text { term memory } \\
\text { A Quick Test } \\
\text { Trail Making Test } \\
\text { Digit Forward Test } \\
\text { Digit Backward Test } \\
\text { D2 test }\end{array}$ & $\begin{array}{l}n=69 \\
40 \text { CLBP } \\
29 \text { No Pain } \\
\text { Age } 18-54\end{array}$ & $\begin{array}{l}\text { The effect of Middle Eastern } \\
\text { culture on the cognitive } \\
\text { abilities of patients with } \\
\text { chronic pain was negligible. }\end{array}$ & $\begin{array}{l}\text { VAS: } \\
\text { Test-retest reliability } r=0.94 \\
\text { CMT: } \\
\text { Test-retest reliability = 0.74-0.87 } \\
\text { Trail Making Test- Test-retest } \\
\text { reliability = 0.70-0.78; inter-rater } \\
\text { reliability = 0.96-0.98. } \\
\text { Digit Forward Test } \\
\text { Digit Backward Test } \\
\text { Test-retest reliability }(r)=0.43- \\
0.77 . \\
\text { D2 test: Cronbach's } \alpha= \\
0.95-0.98, \text { and a Spearman's } \\
\text { coefficient of } 0.47\end{array}$ \\
\hline $\begin{array}{l}\text { Schiltenwolf M, et } \\
\text { al. } 2017 \text { [19] }\end{array}$ & $\begin{array}{l}\text { Multiple choice } \\
\text { vocabulary test } \\
\text { (MWT-B,17) } \\
\text { Wechsler Adult } \\
\text { Intelligence Scale } \\
\text { (WAIS-III) } \\
\text { Trail-making test } \\
\text { (TMT) } \\
\text { CANTAB tests }\end{array}$ & $\begin{array}{l}\mathrm{n}=58,33 \\
\text { CLBP and } 25 \\
\text { healthy controls } \\
\text { Age: } 20 \text { to } 70 \\
\text { years }\end{array}$ & $\begin{array}{l}\text { CLBP patients typically } \\
\text { presented with maladaptive } \\
\text { primary physical and } \\
\text { secondary cognitive } \\
\text { compensations for their pain } \\
\text { disorders that become a } \\
\text { mechanism for ongoing pain. } \\
\text { For this group, specifically } \\
\text { targeted physiotherapy } \\
\text { interventions and cognitive } \\
\text { behavior therapy, have the } \\
\text { potential to impact on both the } \\
\text { physical and cognitive drives } \\
\text { of pain, leading to resolution } \\
\text { of the disorder }\end{array}$ & $\begin{array}{l}\text { (WAIS-III): test-retest } \\
\text { reliabilities ranged from } 0.70 \\
\text { ( } 7 \text { subscales) to } 0.90(2 \\
\text { subscales). } \\
\text { CANTAB tests: } \\
\text { Test-retest reliability }=0.71- \\
0.89) \text {. }\end{array}$ \\
\hline $\begin{array}{l}\text { Cherkin DC, et al. } \\
2017 \text { [20] }\end{array}$ & $\begin{array}{l}\text { Modified Roland } \\
\text { Disability } \\
\text { Questionnaire [RDQ] }\end{array}$ & $\begin{array}{l}n=342 \text { CLBP } \\
\text { Age: } 20-70 \\
\text { years }\end{array}$ & $\begin{array}{l}\text { Participants randomized } \\
\text { to CBT compared with } \\
\text { usual care showed greater } \\
\text { improvement in function } \\
\text { (adjusted mean difference in } \\
\text { change, }-1.84 \text { [ } 95 \% \mathrm{Cl},-3.32 \\
\text { to }-0.37] \text { ). MBSR did not differ } \\
\text { significantly from usual care or } \\
\text { CBT at } 2 \text { years }\end{array}$ & Test Retest reliability $0.68-0.75$ \\
\hline $\begin{array}{l}\text { Spindler M, et al. } \\
2018 \text { [13] }\end{array}$ & $\begin{array}{l}\text { Allgemeine } \\
\text { Depressionsskala } \\
\text { (ADS-K) }\end{array}$ & $\begin{array}{l}\mathrm{n}=42 \text { Chronic } \\
\text { Pain }(\mathrm{CP}) \\
\text { Age: } 33-68 \\
\text { years }\end{array}$ & $\begin{array}{l}\text { This article presents new } \\
\text { insight on which cognitive } \\
\text { mechanisms are influenced } \\
\text { by CP with the focus on } \\
\text { numerical spatial abilities. It } \\
\text { could therefore provide useful } \\
\text { knowledge in developing } \\
\text { new pain assessment tools } \\
\text { specifically for patients } \\
\text { suffering from CP. }\end{array}$ & Cronbach's Alpha $>0.90$ \\
\hline $\begin{array}{l}\text { Hampel P, } 2019 \\
{[14]}\end{array}$ & $\begin{array}{l}\text { German version } \\
\text { of the Center for } \\
\text { Epidemiological } \\
\text { Studies Depression } \\
\text { Scale (CES-D) }\end{array}$ & $\begin{array}{l}n=583 \text { CLBP } \\
\text { Age: } 28-64\end{array}$ & $\begin{array}{l}\text { Patients with high levels of } \\
\text { depressive symptoms showed } \\
\text { improvements in depressive } \\
\text { symptoms and self-efficacy, } \\
\text { supporting the psychological } \\
\text { effectiveness of both } \\
\text { interventions. However, the } \\
\text { beneficial long-term effects of } \\
\text { rehabilitation on work ability } \\
\text { and pain-related DSL among } \\
\text { the IG support implementation } \\
\text { of combined pain competence } \\
\text { and depression prevention } \\
\text { training }\end{array}$ & Cronbach's $\alpha=0.91$ \\
\hline
\end{tabular}


${ }^{1}$ Various outcome measures and their psychometric properties used for assessing cognition in CLBP.

${ }^{2}$ survey of pain attitudes (SOPA)

The pain catastrophising scale (PCS)

Goal Systems Assessment Battery (GSAB)

Center for Epidemiological Studies Depression Scale (CES-D)

Visual analogue scale (VAS)

Contextual Memory Test (CMT)

Multiple choice vocabulary test (MWT-B, 17)

Wechsler Adult Intelligence Scale (WAIS-III)

Trail-making test (TMT)

Modified Roland Disability Questionnaire [RDQ]

the Straight Leg Raise (SLR) and standing forward bending range. The PCS is a self-report questionnaire that assesses unhelpful coping strategies and catastrophic thinking about pain and injury and has strong construct validity, reliability and stability [21]. A strong relationship existed between change in pain attitudes and beliefs, and SLR and forward bending. The cognitive variables explained $77 \%$ and $60 \%$ of the variance in SLR and forward bending, respectively [12].

One Study used 24 items Modified Roland Disability Questionnaire [MRDQ] for assessing effect of Cognitive Behavior Therapy in CLBP. The MRDQ assesses specific physical problems, and not cognitive problems. Test Retest reliability 0.68-0.75 [22].

One study used a CANTAB test which is a series of computerized tests of cognition that runs on a personal computer fitted with a touch-sensitive screen. The results suggest that some, but not all, measures are suitable for cognitive assessment and monitoring in CLBP population [19].

\section{Discussion}

Most studies appeared to employ a broad approach in assessing CLBP-related cognition. Studies included in the review used various assessment tools that have measured cognitive behavior such as depression, memory, functional abilities and catastrophic pain. We could not find any specific assessment tool that has all the components of cognition specific to CLBP and that can provide better vision for the application of CBT.

\section{Main Findings}

A few research requirements and gaps thought to be of particular importance are measuring the "comprehensive evaluation of underlying domains of the relationship between pain and cognition" is a challenge in this field. The exact mechanisms that underpin the complex relationship between pain and cognition are not understood. Most of the tests used in the studies were related to working memory, depression, and attention deficit. But how do we investigate the specific nature of the deficits? Unhelpful cognitions of pain should be taken into consideration when assessing clinical evaluations. The present review considers an intensifying but still limited area of research exploring the potential cognitive impacts of CLBP, and seeks to determine in which areas of functioning there is evidence of a significant relationship between CLBP and cognitive performance. In addition, no assessment tool is found to have all the components of cognition that might be involved in the CLBP.

\section{Comparison with previous literature}

One study used the brief survey of pain attitudes (SOPA) as a sensitive and valid measure of attitudes and beliefs about pain. SOPA is a well-researched instrument that assesses patient feelings about pain control, solicitude (solicitous responses from others in response to one's pain), medication (as appropriate treatment for pain), pain-related disability, pain and emotions (the interaction between emotions and pain), medical cures for pain, and pain-related harm (pain as an indicator of physical damage or harm) [23]. Though this tool does not evaluate concepts of pain physiology but still it can be used for CLBP for better understanding of cognitive behaviors and treatment outcome [8]. Clearly, cognitive impairment in people with chronic pain needs to be investigated in a standardized and targeted manner, and it seems we need to develop different paradigms in order to untangle the physiological mechanisms associated with behavioral deficits.

Paul Karoly, et al., 2008 used GSAB and CES-D for assessing pain induced severity. Results of this study suggested that pain-induced fear is a means of forestalling disability and depression. It is recommended that in treating patients with pain-related fears, it might be useful and cost-effective to assess their current goal appraisals and inter-goal conflicts [17]. Depression is just one of the components in the assessment of cognition and which can have other possible origins than pain [24]. This suggests that neuropsychological tests may not be specific to the constructs or that people with chronic pain have similar deficits in most constructs [25].

Marcus Schiltenwolf in 2017 highlighted in his study that chronic pain seems to impair both information processing and working memory. He also mentioned that there are interactions of cognitive function with pain, depression, anxiety, and medication. So, Multidisci- 
plinary pain therapy may improve impaired cognitive function. However, this study did not consider the nature of the onset of the condition (sudden versus gradual). This study used different Neuropsychological tests based on IQ testing and reaction time testing, which may not be reliable enough for the use in musculoskeletal conditions like low back pain as the component of pain influencing cognition is missing in all the tests [20].

Cherkin DC in 2017 used the modified Roland Disability Questionnaire [RDQ]) to evaluate the result of $C B T$ in chronic low back pain patients. RDQ is a disability scale that scores patients with functional limitations. It will not generate the data required for the assessment of cognition measures. According to the research report by Megan Davidson, the Roland-Morris Disability Questionnaire did not have sufficient reliability to be recommended as clinical outcome measures for individual patients [16].

\section{Strength}

The authors included studies using qualitative methodology in the review which is appropriate considering the research question was aimed at understanding the subjective experience and perceived consequences. The authors searched Pubmed, CINAHL and Medline databases which are appropriate for the topic under investigation. They also reviewed the reference lists of the relevant papers to identify any additional qualitative studies.

\section{Limitations}

Some of the studies included in the review lacked information about the specific steps involved in the methodological analysis and procedures around theoretical saturation - thus questioning the reliability and the validity of the findings of those studies included.

\section{Conclusion}

This review shows that there are few studies that have investigated the relationship of affection of Cognition in chronic low back pain, which indicates the need for further research. Although not highly consistent, the results from the included studies point to any valid assessment tool for measuring Cognition in chronic low back pain. We recommend further studies using other instruments developed specifically to identify components of cognition that can be altered in chronic pain of musculoskeletal origin.

\section{Declaration of Interest}

The authors declare no conflict of interest.

\section{Funding}

Nil.

\section{Competing Interests}

Nil.

\section{References}

1. Moriarty O, McGuire BE, Finn DP (2011) The effect of pain on cognitive function: A review of clinical and preclinical research. Prog Neurobiol 93: 385-404.

2. Hoelscher TJ, Lichstein KL, Rosenthal TL (1984) Objective versus subjective assessment of relaxation compliance in anxious individuals. Behav Res Ther 22: 187-193.

3. Susan H, Picavet J, Vlaeyen WS, Schouten J (2002) Pain Catastrophizing and Kinesiophobia: Predictors of Chronic Low Back Pain. Am J Epidemiol 156: 1028-1034.

4. Kornblith SJ, Rehm LP, O'Hara MW, Danuta M Lamparski (1983) The contribution of self-reinforcement training and behavioral assignments to the efficacy of self-control therapy for depression. Cognit Ther Res 7: 499-528.

5. Neimeyer RA, Kazantzis N, Kassler DM, Kurt D Baker, Richard Fletcher (2008) Group cognitive behavioural ther-apy for depression outcomes predicted by willingness to engage in homework, compliance with homework, and cognitive restructuring skill acquisition. Cogn Behav Ther 37: 199215.

6. Kazantzis N, Deane FP, Ronan KR (2004) Assessing compliance with homework assign-ments. J Clin Psychol 60: 627-641.

7. Day MA, Lang CP, Newton-John TR, Ehde DM, Jensen MP (2017) A content review of cognitive process measures used in pain research within adult populations. Eur J Pain 21: 45-60.

8. Kazantzis N, Whittington C, Zelencich L, Michael Kyrios, Peter J Norton, et al. (2016) Quantity and quality of homework compliance: a meta-analysis of relations with outcome in cognitive behaviour therapy. Behav Ther 47: 755-772.

9. Kendall PC, Korgeski GP (1979) Assessment and cognitive-behavioral interventions. Cognitive Therapy and Research 3: 1-21.

10. Gatchel RJ, Peng YB, Peters ML, Fuchs PN, Turk DC (2007) The biopsychosocial approach to chronic pain: scientific advances and future directions. Psychol Bull 133: 581-624.

11. Rose MJ, Klenerman L, Atchison LE, Slade PD (1992) An application of the fear avoidance model to three chronic pain problems. Behav Res Ther 30: 359-365.

12. Moseley GL (2004) Evidence for a direct relationship between cognitive and physical change during an education intervention in people with chronic low back pain. Eur J Pain 8: 39-45.

13. Spindler M, Koch K, Borisov E, Özyurt J, Sörös P, et al. (2018) The influence of chronic pain and cognitive function on spatial-numerical processing. Front Behav Neurosci 12: 165.

14. Hampel P, Köpnick A, Roch S (2019) Psychological and work-related outcomes after inpatient multidisciplinary rehabilitation of chronic low back pain: a prospective randomized controlled trial. BMC Psychology 7: 6 .

15. McCracken LM, Morley S (2014) The psychological flexibility model: a basis for integration and progress in psychological approaches to chronic pain management. J Pain 15: 221-234.

16. Crombez G, Eccleston C, Van Damme S, Vlaeyen JW, Karoly $P$ (2012) Fear-avoidance model of chronic pain: The next generation. Clin J Pain 28: 475-483. 
17. Karoly P, Okun MA, Ruehlman LS, Pugliese JA (2008) The impact of goal cognition and pain severity on disability and depression in adults with chronic pain: An examination of direct effects and mediated effects via pain-induced fear. Cognitive Therapy and Research 32: 418-433.

18. Nadar MS, Jasem Z, Manee FS (2016) The cognitive functions in adults with chronic pain: a comparative study. Pain Res Manag.

19. Schiltenwolf M, Akbar M, Neubauer E, Gantz S, Flor H, et al. (2017) The cognitive impact of chronic low back pain: positive effect of multidisciplinary pain therapy. Scand $\mathrm{J}$ Pain 17: 273-278.

20. Cherkin DC, Anderson ML, Sherman KJ, Balderson BH, Cook AJ, et al. (2017) Two-year follow-up of a randomized clinical trial of mindfulness-based stress reduction vs cognitive behavioral therapy or usual care for chronic low back pain. JAMA 317: 642-644

21. Adams VJ, Walker B, Jepson D, Cooper C, Tyler J, et al. (2017) Measurement characteristics and clinical utility of the pain catastrophizing scale in individuals experiencing low Back pain. Archives of Physical Medicine and Rehabilitation 98: 2350-2351.

22. Roland M, Fairbank J (2000) The Roland-Morris disability questionnaire and the Oswestry disability questionnaire. Spine 25: 3115-3124.

23. Tait RC, Chibnall JT (1997) Development of a brief version of the Survey of Pain Attitudes. Pain 70: 229-235.

24. Morin AJ, Moullec G, Maiano C, Layet L, Just JL, et al. (2011) Psychometric properties of the Center for Epidemiologic Studies Depression Scale (CES-D) in French clinical and nonclinical adults. Rev Epidemiol Sante Publique 59: 327-340.

25. Carleton RN, Thibodeau MA, Teale MJ, Welch PG, Abrams MP, et al. (2013) The center for epidemiologic studies depression scale: A review with a theoretical and empirical examination of item content and factor structure. PLoS One 8: e58067. 